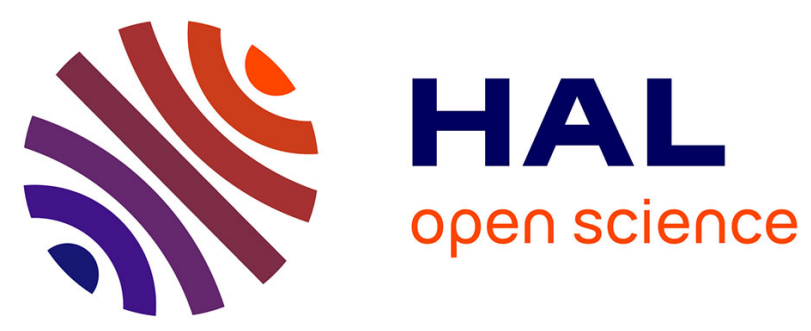

\title{
Why Neurons Are Not the Right Level of Abstraction for Implementing Cognition
}

\author{
Claude Touzet
}

\section{To cite this version:}

Claude Touzet. Why Neurons Are Not the Right Level of Abstraction for Implementing Cognition. Biologically Inspired Cognitive Architectures 2012: Proceedings of the Third Annual meeting of the BICA Society, 196, Springer, pp.317-318, 2013, Advances in Intelligent Systems and Computing, 10.1007/978-3-642-34274-5_54. hal-01338036

\section{HAL Id: hal-01338036 https://hal-amu.archives-ouvertes.fr/hal-01338036}

Submitted on 27 Jun 2016

HAL is a multi-disciplinary open access archive for the deposit and dissemination of scientific research documents, whether they are published or not. The documents may come from teaching and research institutions in France or abroad, or from public or private research centers.
L'archive ouverte pluridisciplinaire HAL, est destinée au dépôt et à la diffusion de documents scientifiques de niveau recherche, publiés ou non, émanant des établissements d'enseignement et de recherche français ou étrangers, des laboratoires publics ou privés. 


\title{
Why Neurons are Not the Right Level of Abstraction for Implementing Cognition
}

\author{
Claude Touzet \\ Aix-Marseille University, France
}

The cortex accounts for $70 \%$ of the brain volume. The human cortex is made of micro-columns, arrangements of 110 cortical neurons (Mountcastle), grouped in by the thousand in so-called macro-colums (or columns) which belong to the same functional unit as exemplified by Nobel laureates Hubel and Wiesel with the orientation columns of the primary visual cortex. The cortical column activity does not exhibit the limitations of single neurons: activation can be sustained for very long periods (sec.) instead of been transient and subject to fatigue. Therefore, the cortical column has been proposed as the building block of cognition by several researchers, but to not effect - since explanations about how the cognition works at the column level were missing. Thanks to the Theory of neuronal Cognition, it is no more the case.

The cortex functionality is cut into small areas: the cortical maps. Today, about 80 cortical maps are known in the primary and secondary cortex [1]. These maps form a hierarchical organization. A cortical map is a functional structure encompassing several thousands of cortical columns. The function of such maps (also known as Kohonen maps) is to build topographic (i.e., organized and localized) representations of the input stimulii (events). This organization is such that similar inputs activate either the same cortical column or neighboring columns. Also, the more frequent the stimulus, the greater the number of cortical columns involved. Each map acts as a novelty detector and a filter. Events are reported as patterns of activations on various maps, each map specialized in a specific "dimension". Spatial and temporal coordinates of events are linked to activations within the hippocampus and define de facto the episodic memory.

Learning is achieved at neuronal level using the famous Hebb's law: "Neurons active in the same time frame window reinforce their connections". This rule does not respect "causality". This, plus the fact that there is at least as much feed-back connections as there are feed-forward ones, explain why a high level cortical activation generates a low level cortical pattern of activations - the same one that would trigger this high level activity. Therefore, our opinion is that the true building block of the cognition is a set of feed-forward and feed-back connections between at least two maps, each map a novelty detector. 
Due to the fact that the real world is mostly continuous (the shorter the time in terval, the smaller the variations) and because the neighboring situations (events) are represented close to each others on the cortical maps, then it is possible to actually "see" and understand activation trajectories (on a map) as representing the various situations encountered (in the real life). It is also straightforward to make a prediction about the coming next situation: the next (column) in line with the current trajectory, and to suppress the transmission to higher levels if successful (in predicting) - therefore reserving higher level maps (such as the ones involved in language) to the processing of the very few events that are non-ordinary (i.e., extraordinary) for the subject. Exterogenous attention is therefore automatically build by to the processing of extraordinary inputs. Endogenous attention is achieved by the mere activation of high level representation, which automatically pre-activates low level localizations (columns) through feed-back connections.

A behavior (i.e., acting) is a sequence of actions related to the achievement of a goal. Any goal can be seen as a situation (to reach). Since situations are associated to columns on maps, a successful behavior is a trajectory on the map that hosts the goal situation, starting from the current situation and ending at the goal situation. The associated actions to perform in order to move from one situation to the next one (closer to the goal) are given by a second map which codes for variations between situations and associated actions [2]. There is no difference implied by the level of abstraction: a mobile robot avoiding obstacles using as a goal a "situation clear of any obstacle" is similar to a person writing a scientific publication using as a goal its "memorization of readers having understood and learned". As evidenced by V. Braitenberg (e.g., its vehicles experiment), anthropomorphism promptly converts to "love", "hatred", "humor", etc. sequences of actions automatically and very simply defined, such as by a few specific goal situations.

Other typically human cognitive abilities are also better understood through the functioning of a hierarchical structure of cortical maps, such as intelligence and consciousness [3], intrinsic motivation [4] or reading [5].

\section{References}

[1] M. Silver and S. Kastner, "Topographic maps in human frontal and parietal cortex," Trends in Cognitive Sciences, Vol. 13, No. 11, 488-495, 2009.

[2] C. Touzet, "Modeling and Simulation of Elementary Robot Behaviors using Associative Memories," International Journal of Advanced Robotic Systems 3(2), 165-170. 2006.

[3] C. Touzet, Consciousness, Intelligence, Free-will: the answers from the Theory of neuronal Cognition, Ed. la Machotte, 156 pages, 2010. (in French) ISBN: 978-2-919411-00-9

[4] C. Touzet, "The Illusion of Joy," in J. Schmidhuber, K.R. Thórisson, and M. Looks (Eds.) Artificial General Intelligence 2011, Springer-Verlag LNAI 6830, pp. 357-362.

[5] S. Dufau, Lete, B., Touzet, C., Glotin, H., Ziegler J.C., and Grainger, J. A., "Developmental Perspective on Visual Word Recognition: New Evidence and a Self-Organizing Model", European Journal of Cognitive Psychology, 22: 5, 669 — 694, 2010. 